Original Research Article

\title{
A Study of drug utilization and clinical outcomes in indoor patients of hypertensive disorders of pregnancy
}

\author{
Smita L. Gaidhankar' ${ }^{1}$, Jaiprakash B. Ramanand ${ }^{1 *}$, Parashram G. Kadam², \\ Ajitkumar M. Zende ${ }^{1}$, Rama R. Bhosale ${ }^{1}$, Nitin N. Puram ${ }^{1}$
}

\begin{abstract}
${ }^{1}$ Department of Pharmacology, R.C.S.M. Government Medical College, Kolhapur, Maharashtra, India

${ }^{2}$ Medical Officer, Savitribai

Phule Municipal Hospital, Kolhapur, Maharashtra, India
\end{abstract}

Received: 25 July 2017

Accepted: 23 August 2017

\section{*Correspondence to:}

Dr. Jaiprakash B. Ramanand, Email: pari27122010@ gmail.com

Copyright: (C) the author(s), publisher and licensee Medip Academy. This is an openaccess article distributed under the terms of the Creative Commons Attribution NonCommercial License, which permits unrestricted noncommercial use, distribution, and reproduction in any medium, provided the original work is properly cited.

\begin{abstract}
Background: Hypertensive disorders of pregnancy are an important determinant of drug use during pregnancy. The aim of study was to assess the clinical outcome and evaluate drug utilization according to WHO core drug prescribing indicators in hypertensive disorders of pregnancy.

Methods: This prospective, observational study in a tertiary care hospital was conducted in 150 pregnant women with hypertensive disorders of pregnancy from January 2014 and December 2014 who fulfilled the inclusion criteria. Antepartum and intrapartum care and the maternal and perinatal outcome were noted. The data was analyzed to evaluate clinical outcome and drug utilization according to WHO core drug use indicators.

Results: Gestational hypertension was most common among hypertensive disorders of pregnancy seen in 62/150 (41.3\%) women. The most common symptom was headache (48\%) while sign noted was edema (69\%). A total of $66 \%$ women had preterm delivery and $42 \%$ babies weighed less than $2.5 \mathrm{~kg}$. Average number of drugs per encounter was 9.7. Percentage of drugs prescribed by generic name and from essential drug list was $64 \%$ and $79 \%$ respectively. The most commonly used drugs were vitamins and minerals prescribed in $100 \%$ patients followed by antihypertensive drugs $(92 \%)$. The most common antihypertensive used were calcium channel blockers and anticonvulsant was magnesium sulphate. Conclusions: There was increased maternal and perinatal morbidity and operative intervention among pregnant women with hypertensive disorders of pregnancy. Most of the drugs were used appropriately and were in accordance with standard guidelines. The important problems identified were inappropriate use of antimicrobials, use of sublingual nifedipine and use of brand names in $1 / 4$ th of prescriptions.
\end{abstract}

Keywords: Drug utilization study, Eclampsia, Hypertension, Magnesium sulphate, Preeclampsia, Pregnancy

\section{INTRODUCTION}

Hypertension is one of the common medical complications of pregnancy and contributes significantly to maternal and perinatal morbidity and mortality.

Globally hypertensive disorders of pregnancy complicate approximately $5-10 \%$ of pregnancies. ${ }^{1}$ Incidence of hypertensive disorders in India is found to be $10.08 .^{2}$
According to The American College of Obstetricians and Gynaecologists (ACOG) practice bulletins, hypertensive disorders of pregnancy are classified as chronic hypertension, preeclampsia-eclampsia, preeclampsia superimposed upon chronic hypertension and gestational hypertension. $^{3}$

Hypertensive disorders of pregnancy are an important cause of severe acute morbidity, long term disability and death among mothers and babies. Women with 
hypertensive disorders of pregnancy are at risk for significant complications, including placental abruption, cerebral haemorrhage, hepatic dysfunction, renal insufficiency, and disseminated intravascular coagulation. The foetal consequences of hypertension include growth retardation, premature birth, and foetal demise. ${ }^{4}$

The identification and effective management of this entity play a significant role in both maternal and foetal outcome. It has been estimated that infants born to women with preexisting or gestational hypertension have a $16 \%$ risk of perinatal death or serious morbidity and with $36 \%$ of them needing "high-level" neonatal care. ${ }^{5}$

A number of drugs in various combinations are used for effective management of hypertensive disorders in pregnancy. There is need to survey the pattern of usage of antihypertensive drugs, to see if the current usage is rational, effective and tolerated and in concordance with current guidelines for treatment of hypertension. The greatest challenge in treating hypertension in pregnancy is to reduce the blood pressure to assure the safety of mother and at same time not to compromise uteroplacental perfusion or cause harmful effects on the foetus.

WHO core drug use prescribing indicators are especially useful in drug utilization research as these indicators measure performance of health care providers in several key dimensions related to the appropriate use of drugs. ${ }^{6}$ Drug utilization evaluation in a given region needs to be an ongoing, continuous process. Despite this, there is paucity of drug utilization studies in indoor patients of hypertensive disorders in pregnancy in Indian scenario. Hence the present study was undertaken with the aim of assessing the clinical outcome and evaluating drug utilization in hypertensive disorders of pregnancy in context to the Indian health care setting.

\section{METHODS}

This prospective, observational study was conducted in the inpatient department of Obstetrics and Gynaecology of a tertiary care Government Hospital during January 2014December 2014. All the participants gave written informed consent to participate in the study.

All pregnant women with hypertensive disorders of pregnancy diagnosed by a senior consulting gynaecologist admitted to obstetric ward and willing to give voluntary informed consent were included as "encounters" and followed for the entire duration of their hospital stay. A total of 150 women were recruited during the entire study period.

Data regarding demographic characteristics, parity, associated medical, surgical, obstetric and gynaecological illness documented in indoor case paper was recorded on the predesigned case record form.
Detailed information regarding clinical features, antepartum and intrapartum care, eclamptic episode, and the maternal and perinatal outcome was obtained from obstetrician, the nursing staff, patient interviews and the inpatient case sheets.

Hypertensive disorders of pregnancy were classified in four main categories as:

1. Gestational hypertension

2. Preeclampsia

3. Severe Preeclampsia

4. Eclampsia

defined as per The ACOG (American College of Obstetricians and Gynaecologists) guidelines for hypertension in pregnancy: ${ }^{3}$

Gestational hypertension was defined as systolic blood pressure of $140 \mathrm{~mm} \mathrm{Hg}$ or higher or diastolic blood pressure of $90 \mathrm{~mm} \mathrm{Hg}$ or higher after 20 weeks of gestation in a woman with a previously normal blood pressure in the absence of proteinuria.

Preeclampsia was defined as systolic blood pressure of to $140 \mathrm{~mm} \mathrm{Hg}$ or higher or diastolic blood pressure of $90 \mathrm{~mm}$ $\mathrm{Hg}$ or higher after 20 weeks of gestation in a woman with a previously normal blood pressure and proteinuria greater than or equal to $300 \mathrm{mg}$ per 24 -hour urine collection or dipstick reading of $1+$ or more.

Severe preeclampsia was defined as systolic blood pressure of $160 \mathrm{~mm} \mathrm{Hg}$ or higher, or diastolic blood pressure of $110 \mathrm{~mm} \mathrm{Hg}$ or higher and thrombocytopenia (platelet count less than 100,000/microliter), impaired liver function as indicated by abnormally elevated blood concentrations of liver enzymes, severe persistent right upper quadrant or epigastric pain unresponsive to medication, progressive renal insufficiency, pulmonary oedema, new-onset cerebral or visual disturbances.

Eclampsia was characterized by the occurrence of generalized seizures in women with preeclampsia, provided that the tonic-clonic seizures are not attributable to other causes.

\section{Drug utilization}

Drugs prescribed to the women each day were entered into a predesigned case record form. Drugs were classified into different classes and their individual generic types. Numbers of drugs prescribed to each patient during the entire duration of hospital stay were calculated. The treatment guidelines recommended by the ACOG were taken into consideration for the management of hypertensive disorders of pregnancy. The evidence gained by the Magpie Trial and the Collaborative Eclampsia Trial was used as standards against which the drug use was measured. ${ }^{7,8}$ 


\section{Statistical analysis}

Data was entered in Microsoft Excel 2008. Frequency and percentages of study parameters were calculated by using descriptive statistics.

\section{RESULTS}

\section{Demographic profile}

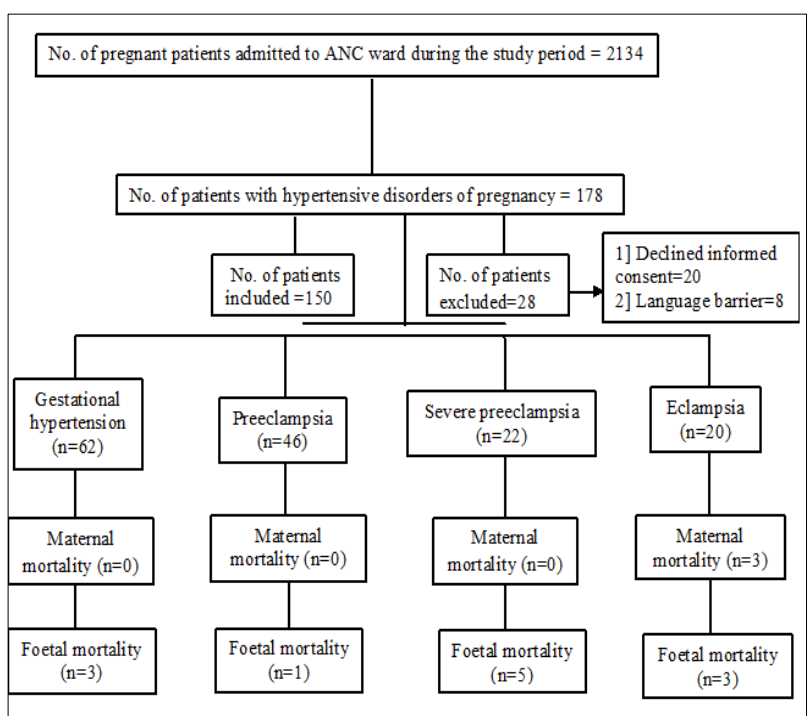

Figure 1: Patient flow diagram.

During the study period of one year, 178 admissions related to hypertensive disorders of pregnancy were recorded. Patient disposition in the study is summarized in Figure 1 and their demographic characteristics in Table 1. The mean age at delivery of the 150 women included in the study was 22 years. Majority of the cases were of gestational hypertension $62(41.3 \%)$, followed by preeclampsia 46 (30.6\%), severe preeclampsia $22(14.6 \%)$ and eclampsia $20(13.3 \%)$. Majority of women $(84 / 150$, $56 \%$ ) were primigravida (Table 1 ).

Table 1: Demographic data of study population $(\mathrm{n}=150)$.

\begin{tabular}{|lll|}
\hline Characteristic & No. of patients & Percentage \\
\hline Age groups (years) & & \\
\hline$<20$ & 40 & 26.6 \\
\hline $20-30$ & 106 & 70.6 \\
\hline$>30$ & 4 & 2.6 \\
\hline Total & 150 & 100 \\
\hline Gravida & & \\
\hline Primigravida & 84 & 56 \\
\hline Multigravida & 66 & 44 \\
\hline Total & 150 & 100 \\
\hline Trimester & & \\
\hline Second & 4 & 2.66 \\
\hline Third & 146 & 97.33 \\
\hline Total & 150 & 100 \\
\hline
\end{tabular}

\section{Clinical features}

The clinical features are summarized in Table 2. Headache was most common symptom in all four groups of gestational hypertension $(32.2 \%)$ preeclampsia $(69.5 \%)$, severe preeclampsia $(81.8 \%)$ and eclampsia $(85 \%)$, while most common sign was edema in gestational hypertension $(51.6 \%)$ preeclampsia (65\%), severe preeclampsia (100\%) and eclampsia (100\%). Proteinuria was found to be significantly more common in eclampsia, severe preeclampsia and preeclampsia as compared with gestational hypertension (Table 2).

Table 2: Clinical features of study population $(n=150)$.

\begin{tabular}{|llllll|}
\hline $\begin{array}{l}\text { Symptoms and } \\
\text { signs }\end{array}$ & Total $\mathbf{n}(\%)$ & $\begin{array}{l}\text { Gestational } \\
\text { hypertension } \mathbf{n}(\%)\end{array}$ & $\begin{array}{l}\text { Preeclampsia } \\
\mathbf{n}(\%)\end{array}$ & $\begin{array}{l}\text { Severe Preeclampsia } \\
\mathbf{n}(\%)\end{array}$ & $\begin{array}{l}\text { Eclampsia } \\
\mathbf{n}(\%)\end{array}$ \\
\hline Headache & $87(58)$ & $20(32.2)$ & $32(69.5)$ & $18(81.8)$ & $17(85)$ \\
\hline Epigastric pain & $63(42)$ & $10(16.2)$ & $27(58.6)$ & $12(54.5)$ & $14(70)$ \\
\hline Blurring of vision & $24(16)$ & 0 & $2(4.34)$ & $10(45.4)$ & $12(60)$ \\
\hline Giddiness & $53(35.3)$ & $5(8)$ & $10(21.7)$ & $18(81.8)$ & $20(100)$ \\
\hline Edema & $104(69.3)$ & $32(51.6)$ & $30(65.2)$ & $22(100)$ & $20(100)$ \\
\hline Hyperreflexia & $37(24.6)$ & 0 & $4(8.69)$ & $15(68.1)$ & $18(90)$ \\
\hline Proteinuria & $90(60)$ & 0 & $46(100)$ & $22(100)$ & $20(100)$ \\
\hline
\end{tabular}

\section{Maternal and perinatal outcome}

Maternal and perinatal outcome features are summarized in Table 3. Regarding maternal outcome, mortality was observed in 3/20 (15\%) women in eclampsia group, while none in gestational hypertension, preeclampsia and severe preeclampsia group. A total of $25 \%$ of patient in eclampsia group and $9 \%$ of patient in severe preeclampsia group required admission to intensive care unit. The most common mode of the delivery in all the groups was through lower segment caesarean section (LSCS) (Table 3). 
The foetal mortality was high in eclampsia $(25 \%)$ and severe preeclampsia group $(22.7 \%)$ as compared with preeclampsia $(0 \%)$ and gestational hypertension group (3\%) Foetal distress and intrauterine growth retardation were more common in eclampsia, severe preeclampsia and preeclampsia than gestational hypertension. A total of $38.6 \%$ of the newborn were having birth weight between 1.5 and $2.5 \mathrm{~kg}$ which was consequent with their premature birth.

Table 3: Clinical outcome of women with hypertensive disorders of pregnancy $(n=150)$.

\begin{tabular}{|c|c|c|c|c|c|}
\hline Clinical outcome & $\begin{array}{l}\text { Total } \\
\text { n }(\%)\end{array}$ & $\begin{array}{l}\text { Gestational } \\
\text { hypertension n (\%) }\end{array}$ & $\begin{array}{l}\text { Preeclampsia } \\
\text { n }(\%)\end{array}$ & $\begin{array}{l}\text { Severe preeclampsia } \\
\text { n }(\%)\end{array}$ & $\begin{array}{l}\text { Eclampsia } \\
\text { n (\%) }\end{array}$ \\
\hline \multicolumn{6}{|l|}{ Period of gestation } \\
\hline Preterm & $99(66)$ & $42(67.7)$ & $29(63)$ & 17(77.2) & $11(55)$ \\
\hline Term & $51(34)$ & $20(32.2)$ & $17(36.9)$ & $5(22.7)$ & $9(45)$ \\
\hline \multicolumn{6}{|l|}{ Maternal outcomes } \\
\hline Mortality & $3(2)$ & $0(0)$ & $0(0)$ & $0(0)$ & $3(15)$ \\
\hline ICU admission & $7(4.6)$ & $0(0)$ & $0(0)$ & 2(9) & $5(25)$ \\
\hline \multicolumn{6}{|l|}{ Mode of delivery } \\
\hline SVD & $44(29.3)$ & $24(38.7)$ & $14(30.4)$ & $1(4.5)$ & $5(25)$ \\
\hline Induced VD & $27(18)$ & $7(11.2)$ & $7(15.2)$ & $8(36.3)$ & $5(25)$ \\
\hline LSCS & $79(52.6)$ & $31(50)$ & $25(54.3)$ & $13(59)$ & $10(50)$ \\
\hline \multicolumn{6}{|l|}{ Perinatal outcomes } \\
\hline Fetal distress & $28(18.6)$ & $0(0)$ & $10(21.7)$ & $8(36.3)$ & $10(50)$ \\
\hline IUGR & $40(26.6)$ & $12(19.3)$ & $15(32.6)$ & $7(31.8)$ & $6(30)$ \\
\hline Fetal death & $12(8)$ & $2(3.2)$ & $0(0)$ & $5(22.7)$ & $5(25)$ \\
\hline \multicolumn{6}{|l|}{ Birth weight (kg) } \\
\hline$<1.5$ & $6(4)$ & $0(0)$ & $6(13)$ & 0 & 0 \\
\hline $1.5-2.49$ & $58(38.6)$ & $21(33.8)$ & $19(41.3)$ & $12(54.5)$ & $6(30)$ \\
\hline$>2.5$ & $74(49.3)$ & $41(66.1)$ & $19(41.3)$ & $5(22.7)$ & $9(45)$ \\
\hline
\end{tabular}

Values are expressed as numbers and percentages

$\mathrm{ICU}=$ intensive care unit, IUGR $=$ Intrauterine growth retardation, $\mathrm{LSCS}=$ Lower segment caesarean section, $\mathrm{SVD}=$ Spontaneous vaginal delivery, VD = Vaginal delivery, IUGR = Intrauterine growth retardation

\section{Drug prescription characteristics}

Table 4 shows the World Health Organization (WHO) core drug prescribing indicators. Average number of drugs per encounter was 9.7. Percentage of drugs prescribed by generic name and from essential drug list was $64.7 \%$ and $79.41 \%$ respectively. Percentage of encounters with an antibiotic and an injection prescribed was $62 \%$ and $52.6 \%$ respectively.

\section{Table 4: WHO core drug prescribing indicators.}

\begin{tabular}{|ll|}
\hline Prescribing indicator & Value \\
\hline Average number of drugs per encounter & 9.7 \\
\hline $\begin{array}{l}\text { Percentage of drugs prescribed by generic } \\
\text { name }\end{array}$ & $64.77 \%$ \\
\hline $\begin{array}{l}\text { Percentage of encounters with an antibiotic } \\
\text { prescribed }\end{array}$ & $62 \%$ \\
\hline $\begin{array}{l}\text { Percentage of encounters with an injection } \\
\text { prescribed }\end{array}$ & $52.6 \%$ \\
\hline $\begin{array}{l}\text { Percentage of drugs prescribed from } \\
\text { essential drug list }\end{array}$ & $79.4 \%$ \\
\hline
\end{tabular}

Table 5 shows overall pattern of drug use in study population. Vitamin and calcium supplements are the most common class of the drugs prescribed in all the groups (100\%), followed by antihypertensive drugs (92.6\%). Antimicrobial (62.6\%) were the next most frequently prescribed drugs while anticonvulsants were prescribed in all cases of eclampsia and also represent the next most common class of drugs in case of eclampsia. Gastroprotective $(60 \%)$, and analgesics $(60 \%)$ constituted the other classes of drugs prescribed in these patient populations.

\section{Prescription pattern of antihypertensive agents}

The prescription pattern of individual antihypertensive and anticonvulsant drugs is described in table 6. All the patients of severe preeclampsia and eclampsia were prescribed antihypertensives while $97 \%$ patients of preeclampsia and $82 \%$ patients of gestational hypertension were prescribed antihypertensives. Calcium channel blocker nifedipine was the most frequently prescribed antihypertensive (94.6\%), followed by sympatholytic alpha methyldopa (30.6\%) and $\beta$-blockers labetolol and atenolol $(18.6 \%)$. Majority of the patients $(53.9 \%)$ were 
managed with monotherapy but $44.6 \%$ required combination therapy.

\section{Prescription pattern of anticonvulsant drugs}

The anticonvulsant drugs were prescribed in $34 \%$ patients. Magnesium sulphate $\left(\mathrm{MgSO}_{4}\right)$ alone was clearly the anticonvulsant of choice, prescribed in $28.6 \%$ women. All
$(100 \%)$ of the patients with eclampsia received magnesium sulphate either alone or in combination with phenytoin, while $63 \%$ patient with severe preeclampsia, $21 \%$ patient with preeclampsia and $11 \%$ patients of gestational hypertension received it (Table 6). The cases showing recurrence of seizures, while on magnesium sulphate therapy were simultaneously put on intravenous phenytoin therapy. The duration of Magnesium sulphate therapy was quite variable.

Table 5: Overall pattern of drug use in study population $(n=150)$.

\begin{tabular}{|llllll|} 
Drug class & $\begin{array}{l}\text { Total } \\
\mathbf{n}(\%)^{*}\end{array}$ & $\begin{array}{l}\text { Gestational } \\
\text { hypertension n }(\%)\end{array}$ & $\begin{array}{l}\text { Preeclampsia } \\
\mathbf{n}(\%)\end{array}$ & $\begin{array}{l}\text { Severe preeclampsia } \\
\mathbf{n}(\%)\end{array}$ & $\begin{array}{l}\text { Eclampsia } \\
\mathbf{n}(\%)\end{array}$ \\
\hline Vitamins and minerals & $150(100)$ & $62(100)$ & $46(100)$ & $22(100)$ & $20(100)$ \\
\hline Antihypertensive drugs & $139(92)$ & $51(82)$ & $45(97)$ & $22(100)$ & $20(100)$ \\
\hline Antimicrobial agents & $94(92.6)$ & $26(41.9)$ & $27(58.6)$ & $21(95.4)$ & $20(100)$ \\
\hline Gastroprotectives drugs & $90(60)$ & $24(38.7)$ & $27(58.6)$ & $20(90)$ & $19(95)$ \\
\hline Analgesics & $91(60)$ & $24(38.7)$ & $2145.6)$ & $21(95.4)$ & $19(95)$ \\
\hline Anticonvulsant drugs & $51(34)$ & $7(11.2)$ & $10(21.7)$ & $14(63.6)$ & $20(100)$ \\
\hline
\end{tabular}

Table 6: Prescription pattern of antihypertensive and anticonvulsant drugs.

\begin{tabular}{|lllll|l|}
\hline Drug & $\begin{array}{l}\text { Total } \\
\mathbf{n}(\%)\end{array}$ & $\begin{array}{l}\text { Gestational } \\
\text { hypertension n }(\%)\end{array}$ & $\begin{array}{l}\text { Preeclampsia } \\
\mathbf{n}(\%)\end{array}$ & $\begin{array}{l}\text { Severe } \\
\text { preeclampsia } \mathbf{n}(\%)\end{array}$ & $\begin{array}{l}\text { Eclampsia } \\
\text { n (\%) }\end{array}$ \\
\hline Nifedipine monotherapy & $75(50)$ & $26(41.9)$ & $28(60.8)$ & $8(36.3)$ & $13(65)$ \\
\hline Nifedipine+Methyldopa & $39(26)$ & $20(32.2)$ & $9(19.5)$ & $7(31.8)$ & $3(15)$ \\
\hline Nifedipine+ Labetalol & $15(10)$ & $4(6.4)$ & $4(8.6)$ & $4(18.1)$ & $3(15)$ \\
\hline $\begin{array}{l}\text { Nifedipine+ Labetalol+ } \\
\text { Methyldopa }\end{array}$ & $7(4.6)$ & $1(1.6)$ & $3(6.5)$ & $2(9)$ & $1(5)$ \\
\hline Nifedipine+atenolol & $6(4)$ & $0(0)$ & $1(2.17)$ & $1(4.5)$ & $4(20)$ \\
\hline $\mathrm{MgSO}_{4}$ alone & $43(28.6)$ & $7(11.2)$ & $10(21.7)$ & $14(63.6)$ & $12(60)$ \\
\hline $\mathrm{MgSO}_{4}+$ phenytoin & $8(5.3)$ & $0(0)$ & $0(0)$ & $0(0)$ & $8(40)$ \\
\hline
\end{tabular}

\section{Prescription pattern of antibiotics}

Out of $62 \%$ patients who received antimicrobial drug the most frequently used drug was amoxicillin in $22.6 \%$. The third generation cephalosporin ceftriaxone given intravenously for five days followed by oral amoxicillin for 3 days was the regimen used in all patients who underwent caesarean section.

\section{DISCUSSION}

The role of drug utilization studies in improving health care is now well accepted. Evaluating various qualitative and quantitative aspects of drug utilization in women with hypertensive disorders of pregnancy is important for several reasons. Firstly, Hypertensive disorders of pregnancy which have the potential to adversely affect mother and/or foetus must be managed effectively and timely in order to reduce maternal and foetal morbidity and mortality. Secondly pharmacological interventions are necessary for effective management of hypertensive disorders of pregnancy. And lastly it is important to protect the unborn foetus from harmful effects of drugs to the greatest possible extent. The primary objective of management in women with hypertensive disorders of pregnancy is to protect the safety of the mother and the foetus and the subsequent delivery of a healthy baby. The reported outcomes of indoor patients with hypertensive disorders of pregnancy are limited. To add to this body of literature, we reviewed the obstetric outcome and drug utilization of 150 indoor patients with hypertensive disorders of pregnancy at our institution.

This prospective, observational, hospital based study involved 150 pregnant women with hypertensive disorders of pregnancy. Hypertensive disorders of pregnancy have been found to be more common in young primigravid women, consistent with the current findings that $82 \%$ of patients were $\leq 25$ years old and $56 \%$ were primigravidas. Similar results have been reported by previous studies. ${ }^{9}$

The average number of the prescribed medications is too high (9.7). However, this can be due to the fact that this number includes prescribed haematinics and calcium tablets, gastroprotectives, antihypertensives, antibiotics as well as anticonvulsants. Moreover, these represent the 
numbers of different drugs prescribed to each patient during the entire duration of the hospital stay.

Most of the women attending this hospital come from lower socioeconomic class. High prevalence of poor nutritional status, vitamin and mineral deficiencies in this class warrants prophylactic use of vitamins and minerals. ${ }^{10}$ Accordingly most commonly used medications (in $100 \%$ of women) in the present study were iron, folic acid, calcium and multivitamin B complex (Table 5). Our results are in accordance with previous Indian studies. ${ }^{9,11}$

The values of percentage of drugs prescribed by generic name $(64.7 \%)$ and percentage of drugs prescribed from essential drug list $(79.4 \%)$ in the present study are closer to values $(62.8 \%$ and $80.79 \%)$ reported by study of Patel et al. ${ }^{9}$ As higher percentage of drugs were prescribed from essential drugs list, it suggests rationality of drug use pattern and degree to which practices conform to a national drug policy. Prescribing by generic names offers several advantages such as low cost of drug therapy, clear identification of a drug, increased patient adherence. ${ }^{12}$ Despite these advantages, in $36 \%$ of cases prescribing was done by brand names in the present study. This finding point towards need for intervention to improve prescribing practices of physicians. Percentage of encounters with an injection prescribed is $52.6 \%$ which is closer to the value reported by Patel KP. ${ }^{9}$ This higher value is mainly attributed to parenteral antibiotics and magnesium sulphate.

Percentage of encounters with an antibiotic prescribed was $62 \%$. Our study revealed a relatively higher frequency of antibiotic usage. Each patient who underwent caesarean section was prescribed antibiotic for eight days. The trials evaluating the use of prophylactic antibiotics have shown that a single preoperative dose of antibiotic is sufficient and multiple dose regimes do not offer any added benefit to reduce the infectious morbidity. ${ }^{13}$ But the prescribers point to the fact that maximum number of women undergoing emergency caesarean section were unregistered pregnancies, presenting to this particular health facility for the first time, and of low socioeconomic status with no prior antenatal check-up. However, such an excessive use of antibiotic is alarming and irrational. This needs further investigation to curtail the use of antimicrobials in these patients.

The pharmacotherapy of hypertensive disorders in the present study was largely in accordance with standard guidelines, majority of the patients $(53.9 \%)$ were managed with monotherapy but $44.6 \%$ required combination therapy (Table 6). Similar treatment practices have been reported in previous studies by Deb et al in a tertiary care hospital. ${ }^{14}$ Calcium channel blockers were the most common class of antihypertensive prescribed to $53.9 \%$ of the women. Nifedipine was the most common individual antihypertensive prescribed $(75 \%)$ followed by combination of nifedipine and methyldopa (28\%). In the present study, it was surprising to observe the low use of labetalol as antihypertensive drug. With its efficacy, convenient routes of administration and better safety profile in pregnancy, labetalol has become the drug of choice for the acute control of blood pressure in cases of hypertensive disorders of pregnancy worldwide. $^{15}$ According to the prescribers, the high cost of the drug does not allow prescribing it routinely. The use of atenolol early in pregnancy is associated with fetal growth impairment. Most authorities recommend the total avoidance in early pregnancy and cautious use in late pregnancy. ${ }^{3}$ On analysis, it was found that in all $8 \%$ of cases, it was prescribed post delivery.

The good thing in the present study was that none of the contraindicated antihypertensive drugs like angiotensin converting enzyme inhibitors (ACEI), angiotensin receptor blockers and diuretics was prescribed to a single patient. This is in contrast to earlier studies which report use of heterogeneous antihypertensive medications including ACEIs, diuretics and $\beta$ blockers. ${ }^{16}$

In the present study $9.6 \%$ patients with severe hypertension received single dose of sublingual nifedipine which is against the recommendations for rational use of antihypertensive drugs. Rapid acting nifedipine is not recommended for treating hypertension or hypertensive emergencies especially in pregnancy because it has been associated with fatal and nonfatal untoward cardiovascular events as well as maternal hypotension, fetal disorders and compromised fetal perfusion. ${ }^{3}$ Similar use of rapid acting sublingual nifedipine has been reported by Kumar et al in $70 \%$ of study population. ${ }^{17}$ Though the frequency of use of sublingual nifedipine in our study is less compared to study by Kumar et al, it points towards need for appropriate interventions to improve prescribing practices.

Anticonvulsant therapy is indicated both to prevent the occurrence and control of convulsions in preeclampsia and eclampsia. ${ }^{18,19}$ Magnesium sulphate has now become the drug of choice for treating and preventing convulsions in women with preeclampsia/eclampsia. ${ }^{[7]}$ The Collaborative Eclampsia Trial provides strong evidence for the routine use of magnesium sulphate rather than either diazepam or phenytoin for the management of eclampsia. ${ }^{8}$ Magnesium sulphate alone was found to be the most common anticonvulsant being prescribed in $28.6 \%$ patients followed by combination of magnesium sulphate and phenytoin $(5.33 \%)$. This finding was in contrast with study done by Kumar, et al who reported very high use of phenytoin $(69 \%)$ in patients with severe preeclampsia and eclampsia. $^{18}$

\section{CONCLUSION}

In conclusion, there was increased maternal and perinatal morbidity and operative intervention among pregnant women with hypertensive disorders of pregnancy. Gestational hypertension was most common among hypertensive disorders of pregnancy. Vitamins, minerals, antihypertensive drugs and anticonvulsant drugs were most 
commonly used drugs. Most of the drugs were used appropriately and were in accordance with standard guidelines. The important problems identified were inappropriate use of antimicrobials, use of sublingual nifedipine and use of brand names in $1 / 4^{\text {th }}$ of prescriptions. In addition to knowledge obtained from drugs utilization studies like the present study, understanding knowledge, attitude and practices of prescribers and patients can help further to plan effective interventions to improve drug use.

\section{ACKNOWLEDGEMENTS}

Authors would like to thank to Department Obstetrics and Gynecology, Government Medical College and Hospital, Miraj for their co-operation during the study.

Funding: No funding sources

Conflict of interest: None declared

Ethical approval: The study was approved by the Institutional Ethics Committee

\section{REFERENCES}

1. Khan KS, Wojdyla D, Say L, Gulmezoglu AM, Van Look PF. WHO analysis of causes of maternal death: a systematic review. Lancet. 2006;367:1066-74.

2. Gupte S, Wagh G. Preeclampsia-Eclampsia. J Obstet Gynaecol India. 2014;64:4-13.

3. Hypertension in pregnancy. Report of the American College of Obstetricians and Gynecologists' Task Force on Hypertension in Pregnancy. Obstet Gynecol. 2013;122:1122-31.

4. Dutta DC. Hypertensive Disorders in Pregnancy. In: Konar H, editors. DC Dutta's Textbook of Obstetrics. $8^{\text {th }}$ Ed. New Delhi: Jaypee Brothers Medical Publishers; 2015:256-278.

5. Magee LA, von Dadelszen P, Chan S, Gafni A, Gruslin A, Helewa M, et al. CHIPS Pilot Trial Collaborative Group. The control of hypertension in pregnancy study pilot trial. Br J Obstet Gynaecol. 2007;114:13-20.

6. WHO. How to investigate drug use in health facilities: selected drug use indicators. (WHO/DAP/93.1). Geneva: Action Programme on Essential Drugs, World Health Organization; 1993:1-87. Available at: apps.who.int/medicinedocs/en/d/Js2289e/. Accessed 15 February 2015.

7. Altman D, Carroli G, Duley L, Farrell B, Moodley J, Neilson J, et al. Magpie Trial Collaboration Group. Do women with pre-eclampsia, and their babies, benefit from magnesium sulphate? The Magpie Trial: A randomised placebo-controlled trial. Lancet 2002;359:1877-90.

8. Collaboration Group. Do women with pre-eclampsia, and their babies, benefit from magnesium sulphate?
The Magpie Trial: A randomised placebo-controlled trial. Lancet. 2002;359:1877-90.

9. Duley L. Magnesium sulphate regimens for women with eclampsia: Messages from the Collaborative Eclampsia Trial. Br J Obstet Gynaecol. 1996;103:1035.

10. Patel KP. A study of morbidity and drug utilization pattern in indoor patients of high risk pregnancy at tertiary care hospital. Int J Reprod Contracept Obstet Gynecol. 2013;2(3):372-78.

11. Good Clinical Practice Recommendations for Iron Deficiency Anemia in Pregnancy (IDA) in Pregnancy in India. J Obstet Gynaecol India. 2011;61:569-71.

12. Gawde SR, Bhide SS, Patel TC, Chauhan AR, Mayadeo NM, Sawardekar SB. Drug Prescription Pattern in Pregnant Women Attending Antenatal Out Patient Department of a Tertiary Care Hospital. Br J Pharm Res. 2013;3(1):1-12.

13. Haas JS, Phillips KA, Gerstenberger EP, Seger AC. Potential savings from substituting generic drugs for brand-name drugs: medical expenditure panel survey, 1997-2000. Ann Intern Med. 2005;142(11):891-7.

14. Bagratee JS, Moodley J, Kleinschmidt I, Zawilski W. A randomised controlled trial of antibiotic prophylaxis in elective caesarean delivery. BJOG. 2001;108:1438.

15. Deb T, Ghosh A, Bhadra B. Drug utilization study in pregnancy induced hypertension in a tertiary care teaching hospital. JDDT. 2014;4:169-72.

16. Sibai BM, Ross MG. Hypertension in gestational diabetes mellitus: Pathophysiology and long-term consequences. J Matern Fetal Neonatal Med. 2010;23:229-33.

17. Bateman BT, Hernandez-Diaz S, Hybrecht KF. Patterns of outpatient antihypertensive medication use during pregnancy in a Medicaid population. Hypertension. 2012;60:913-20.

18. Kumar S, Bansal D, Hota D, Jain M, Singh P, Pandey BL. Assessment of clinical outcomes and prescribing behavior among in patients with severe preeclampsia and eclampsia: An Indian experience. Indian $\mathbf{J}$ Pharmacol. 2014;46(1):18-23.

19. Sibai BM. Imitators of severe preeclampsia/eclampsia. Clin Perinatol. 2004;31:835-52.

20. Chien PF, Khan KS, Arnott N. Magnesium sulphate in the treatment of eclampsia and pre-eclampsia: An overview of the evidence from randomised trials. $\mathrm{Br} \mathbf{J}$ Obstet Gynaecol. 1996;103:1085-91.

Cite this article as: Gaidhankar SL, Ramanand JB, Kadam PG, Zende AM, Bhosale RR, Puram NN. A Study of drug utilization and clinical outcomes in indoor patients of hypertensive disorders of pregnancy. Int J Basic Clin Pharmacol 2017;6:24017. 